University of Wollongong

Research Online

Faculty of Engineering and Information

Faculty of Engineering and Information

Sciences - Papers: Part A

Sciences

$1-1-2014$

Microgrids of commercial buildings: strategies to manage mode transfer from grid connected to islanded mode

Lasantha Meegahapola

University of Wollongong, lasantha.meegahapola@rmit.edu.au

Duane A. Robinson

University of Wollongong, duane@uow.edu.au

Ashish Agalgaonkar

University of Wollongong, ashish@uow.edu.au

Sarath Perera

University of Wollongong, sarath@uow.edu.au

Philip Ciufo

University of Wollongong, ciufo@uow.edu.au

Follow this and additional works at: https://ro.uow.edu.au/eispapers

Part of the Engineering Commons, and the Science and Technology Studies Commons

Research Online is the open access institutional repository for the University of Wollongong. For further information contact the UOW Library: research-pubs@uow.edu.au 


\title{
Microgrids of commercial buildings: strategies to manage mode transfer from grid connected to islanded mode
}

\begin{abstract}
Microgrid systems located within commercial premises are becoming increasingly popular and their dynamic behavior is still uncharted territory in modern power networks. Improved understanding in design and operation is required for the electricity utility and building services design sectors. This paper evaluates the design requirements for a commercial building microgrid system to facilitate seamless mode transition considering an actual commercial building microgrid system. A dynamic simulation model of the proposed microgrid system is established (utilizing DIgSILENT Power Factory) to aid the development of planning and operational philosophy for the practical system. An economic operational criterion is developed for the microgrid to incorporate selective mode transition in different time intervals and demand scenarios. In addition, a multi-droop control strategy has been developed to mitigate voltage and frequency variations during mode transition. Different system conditions considering variability in load and generation are analyzed to examine the responses of associated microgrid network parameters (i.e., voltage and frequency) with the proposed mode transition strategy during planned and unplanned islanding conditions. It has been demonstrated that despite having a rigorous mode transition strategy, control of certain loads such as direct online (DOL) and variable-speed-drive (VSD) driven motor loads is vital for ensuring seamless mode-transition, in particular for unplanned islanding conditions.
\end{abstract}

\section{Keywords}

connected, manage, islanded, mode, transfer, buildings, grid, commercial, strategies, microgrids

\section{Disciplines}

Engineering | Science and Technology Studies

\section{Publication Details}

L. Gunaruwan. Meegahapola, D. Robinson, A. P. Agalgaonkar, S. Perera \& P. Ciufo, "Microgrids of commercial buildings: strategies to manage mode transfer from grid connected to islanded mode," IEEE Transactions on Sustainable Energy, vol. 5, (4) pp. 1337-1347, 2014. 


\title{
Microgrids of Commercial Buildings: Strategies to Manage Mode Transfer from Grid Connected to Islanded Mode
}

\author{
L.G. Meegahapola, Member, IEEE, D. Robinson, A.P. Agalgaonkar, Senior Member, IEEE, \\ S. Perera, Senior Member, IEEE, P. Ciufo, Senior Member, IEEE
}

\begin{abstract}
Microgrid systems located within commercial premises are becoming increasingly popular and their dynamic behaviour is still uncharted territory in modern power networks. Improved understanding in design and operation is required for the electricity utility and building services design sectors. This paper evaluates the design requirements for a commercial building microgrid system to facilitate seamless mode transition considering an actual commercial building microgrid system. A dynamic simulation model of the proposed microgrid system is established (utilizing DIgSILENT Power Factory) to aid the development of planning and operational philosophy for the practical system. An economic operational criterion is developed for the microgrid to incorporate selective mode transition in different time intervals and demand scenarios. In addition, a multi-droop control strategy has been developed to mitigate voltage and frequency variations during mode transition. Different system conditions considering variability in load and generation are analysed to examine the responses of associated microgrid network parameters (i.e. voltage and frequency) with the proposed mode transition strategy during planned and unplanned islanding conditions. It has demonstrated that despite having a rigorous mode transition strategy, control of certain loads such as direct on-line (DOL) and variable speed-drive (VSD) driven motor loads is vital for ensuring seamless modetransition, in particular for unplanned islanding conditions.
\end{abstract}

Index Terms - Commercial building microgrids, islanded mode, mode transition, solar-photovoltaic (PV), variable-speed drive (VSD).

\section{INTRODUCTION}

$\mathrm{M}$ ICROGRIDS are expected to become an integral part of future electricity networks as they offer network support capabilities by means of multiple distributed energy resources and exhibit capabilities of self-sufficient standalone operation. There are number of microgrid systems, with differing characteristics, which are currently operational around the world [1], [2]. Typically, microgrid systems comprise of one or more renewable and distributed energy resources such as solar photovoltaic systems, wind and gas turbines, controllable and non-controllable loads, and energy storage systems. Microgrids, if designed properly, are capable of operating in either grid connected or islanded mode. In most cases, the generating resources of a microgrid are interfaced through inertialess power electronic converters, which may

L.G. Meegahapola, A. Agalgaonkar, S. Perera, and P. Ciufo are with the Endeavour Energy Power Quality \& Reliability Centre at the University of Wollongong, NSW, 2522, Australia. (e-mail: lasantha@uow.edu.au, ashish@uow.edu.au, sarath@uow.edu.au, ciufo@uow.edu.au).

D.A. Robinson is with the Sustainable Buildings Research Centre at the University of Wollongong, NSW, 2522, Australia (e-mail: duane@uow.edu.au). significantly affect the dynamics and stability of the microgrid especially during mode transition, i.e. from grid-connected to islanded mode or vice versa.

Microgrids can be implemented at various distribution voltage levels, and typically appear at downstream locations within a network, depending upon their application. In practice, microgrid systems are implemented either in the form of laboratory scale prototypes [3]-[5] or to serve remote consumers in a network [6]-[8]. In recent years, microgrids have gained popularity to cater for demand management and economic requirements of commercial building installations, thereby supplementing the conventional grid. The scheduling problem of building energy supplies is considered in [9] with the practical background of a low energy building facilitated by a microgrid. The main objective is to minimize the overall cost for ensuring economic operation of a building over a set timeframe while satisfying the energy balance and complicated operating constraints of individual energy supply equipment and devices in the microgrid. A cost optimisation scheme aimed at reducing the fuel consumption rate of the microgrid system, comprising of reciprocating gas engines, a combined heat and power plant, a photovoltaic array and a wind generator, while constraining it to meet the electrical and thermal energy demand and provide a certain minimum reserve power is proposed in [10]. An analytical technique to evaluate the reliability for customers in a microgrid is proposed in [11], while the development of a novel energy management system based on the application of neural networks is proposed in [12] to determine hourly dispatch of generators within the microgrid for minimizing the global energy costs.

An iterative procedure based on bifurcation theory is proposed in [13] to examine the microgrid stability by assessing the impacts of drooping characteristics meant for frequency and voltage regulation and primary reserve scheduling. Field tests conducted on a laboratory scale microgrid are reported in [14] which demonstrate stable system behaviour at critical operating points, the flexibility of control modes, and the ability of the system to ensure mode transition from islanded mode to grid connected mode in an autonomous manner. The management of mode transition strategies has been investigated in [15], [16] giving due consideration to operational characteristics of microgrids. In [15], authors have adopted an internal voltage controller and a droop based power sharing scheme for seamless mode transition, while the voltage based modified droop control method has been proposed in [16] for the mode transition from islanded to grid connected mode. Most of these studies have mainly focused on controlling the microgrid sources during 
mode transition and have placed less emphasis on the impact of load dynamics within the microgrid. Moreover, microgrids predominantly embedded with intermittent renewable energy resources pose significant challenges in terms of managing the mode transfer.

The microgrid system presented in this study is derived from the prospective scheme designed for the Sustainable Buildings Research Centre (SBRC) at the University of Wollongong, Australia. The proposed system is specifically meant to contribute to the net zero energy target of the SBRC and improve practical understanding of microgrid operation, especially for commercial building scale installations. The generating resources in the proposed microgrid include renewable resources such as rooftop solar-PV and small-scale wind generators, and lithium-ion batteries for energy storage to meet the static and dynamic loads of the building. The proposed microgrid is expected to operate in either gridconnected mode or islanded mode in order to maximize the energy harvesting from renewable energy sources, ensure economically feasible operation, and practically demonstrate various microgrid research activities undertaken at the university. A model of the proposed SBRC microgrid has been developed using DIgSILENT Power Factory in order to evaluate the developed control techniques.

A transitional strategy has been proposed for seamless operation of the microgrid under a commercial building environment. Time domain simulation studies have been conducted in DIgSILENT Power Factory for examining the system performance under different modes of operation. The mode transition affects operational characteristics of the microgrid and quality of power being delivered to the loads are examined through studies. It is envisaged that the critical components of the microgrid such as generators, energy storage systems, and loads require special design considerations to effectively manage mode transition.

The paper is organized as follows: Section II provides a description of the proposed SBRC microgrid system, including some commentary on the design considerations; Section III describes the SRBC microgrid model used for the dynamic simulations; Section IV outlines the conceptual framework for the mode transition strategy proposed for commercial scale microgrids; Section V presents an evaluation of the dynamic performance of the modeled system; Section VI provides some commentary on additional considerations for commercial scale microgrids; and Section VI concludes the work presented in this paper.

\section{SBRC MICROGRID DESIGN CONSIDERATIONS}

This section presents the design considerations of the SBRC microgrid. A special emphasis has been placed on the generation system, energy storage system, and capacitor bank sizing. To assist in the design process and examine the prospective SBRC load profile, field measurements of voltage, current, and active and reactive power were obtained from another commercial building located at the University of Wollongong, which contained similarly configured electrical loads and load types. The measured data has been scaled to match the design details associated with the SBRC facility; however ramp rates related to equipment operation, power factor, etc. remain unchanged. In addition, characteristics of the other dynamic loads are also considered during the modeling study.

The design philosophy of the SBRC microgrid system is primarily based on the net zero energy target of the SBRC building as part of the facility's certification requirements [17]. The net zero energy target is achieved through appropriate sizing of the microgrid's main generation unit, which is made up of several solar-PV systems.

\section{A. Active and Reactive Power Characteristics}

The load profile of the SBRC is proposed to closely match that of the similar building for which a measurement campaign was undertaken. Fig. 1 illustrates the projected real and reactive power demand of the SBRC facility and microgrid.

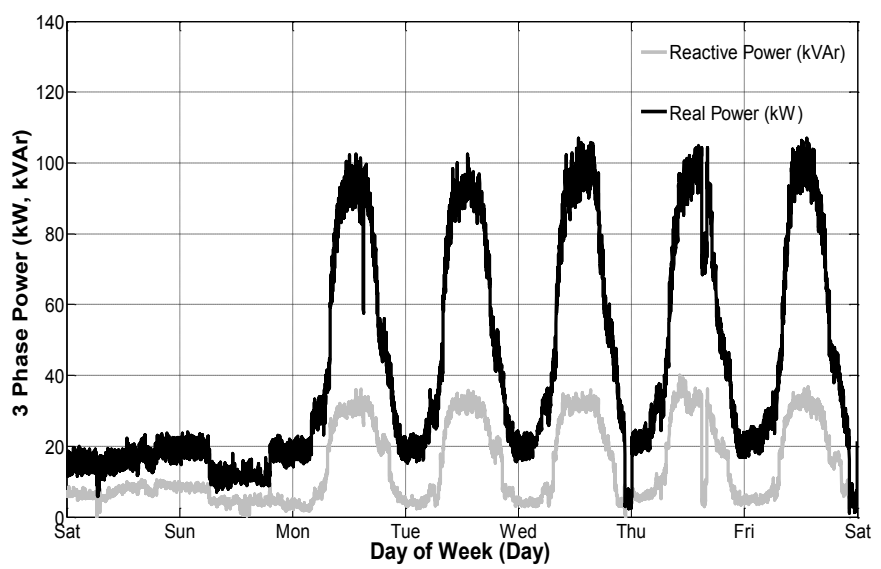

(a)

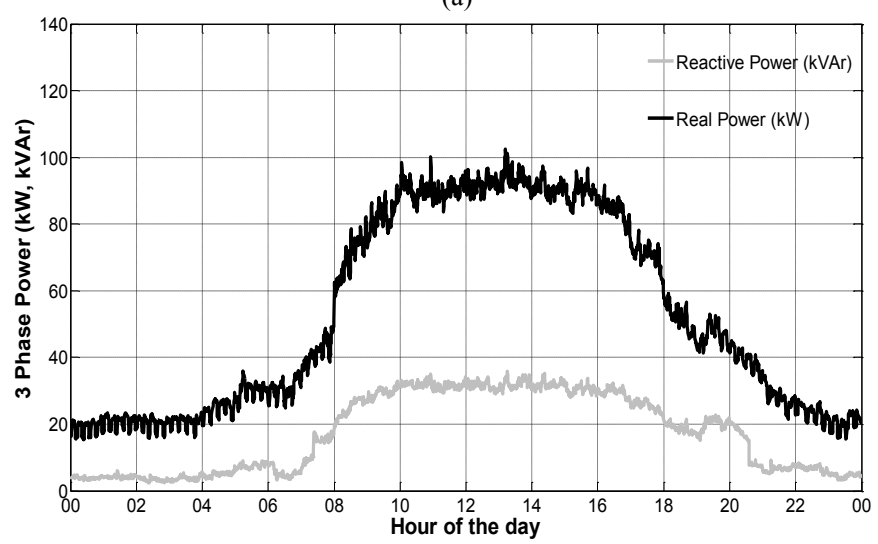

(b)

Fig.1: Projected active and reactive power for SBRC; (a) weekly profile, (b) typical weekday profile.

Table I: Load composition during peak load

\begin{tabular}{c|c}
\hline \hline Load Type & Active Power \\
\hline Computer equipment & $50 \mathrm{~kW}$ \\
\hline Other (Lab equipment) & $30 \mathrm{~kW}$ \\
\hline Lighting & $25 \mathrm{~kW}$ \\
\hline DOL motor load & $87.9 \mathrm{~kW}$ \\
\hline VSD motor load & $21.4 \mathrm{~kW}$ \\
\hline Total & $214.3 \mathrm{~kW}$ \\
\hline \hline
\end{tabular}

Table I illustrates the load composition during peak load period. Approximately $50 \%$ of the installed loads are dynamic loads such as motors; hence it is a significantly challenging especially under issue for mode-transition for the renewable microgrid under study. 


\section{B. Component Sizing}

\section{1) Sizing of localized generation (solar-PV array)}

The annual energy demand for the SBRC facility was determined by making seasonal adjustments to the weekly demand curve of Fig. 1(a) and summating it over a year. A comparison of values derived from peak load data (Table I) and estimated operating times with diversity was also undertaken. An expected total approximated energy demand of 148.1 MWh per year was established.

To ensure net zero energy requirements the solar-PV system was designed to provide adequate supply using minimum monthly figures for solar irradiation. Minimum monthly irradiation was determined from the previous 5-years of solar data obtained from local weather stations. The total installed capacity of solar-PV was selected to be $147 \mathrm{~kW}_{\mathrm{p}}$ for the SBRC microgrid. This included margins for factors such as panel availability, load estimation, and equipment efficiency. It is noted that the SBRC building has been designed to carry significantly more solar-PV capacity, and as such there is potential for future expansion.

The wind turbines associated with the microgrid are treated as experimental generation units and thus were not included in the net-zero energy calculations. Two small-scale wind turbines are proposed for the SBRC microgrid with a nominal rating of $10 \mathrm{~kW}$. Their presence provides some additional margin for meeting the net zero energy requirements, and also assists in reducing required energy storage. It is anticipated that the wind turbines will provide approximately $10-20 \mathrm{MWh}$ per year.

\section{2) Sizing of power factor correction (PFC) capacitors}

To meet utility connection requirements, the reactive power demand of the SRBC facility is compensated using dynamically switched banks of PFC capacitors. It is envisaged that sizing of the PFC capacitors is to be left until actual measurements of the SBRC building demand profiles are available, however, for the purpose of analysis field measurements from the example building have been utilized.

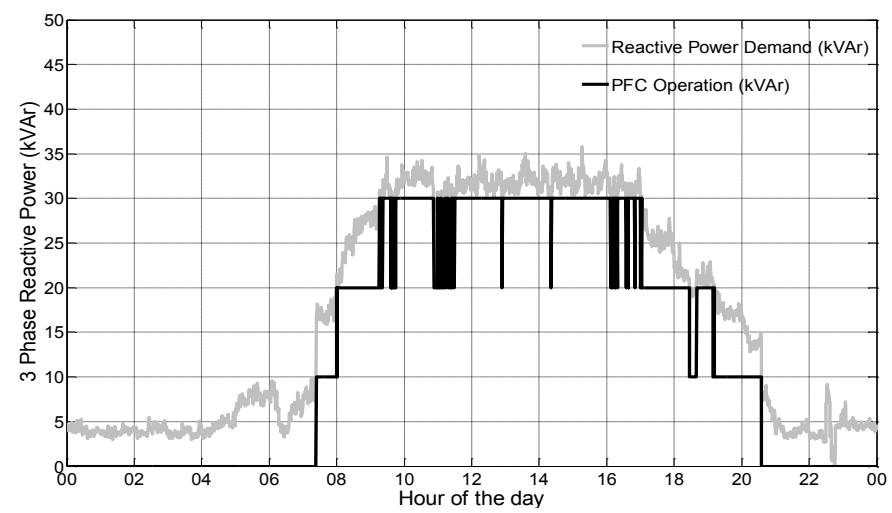

Fig. 2: Reactive power demand and PFC capacitor switching operation.

Six segmented PFC stages are selected to match typical installations at most of the commercial building locations within the university. The peak reactive power demand of the sample building is able to be delivered by the first four segments of PFC capacitors, i.e. $40 \mathrm{kVAr}$. Additional segments (i.e. $20 \mathrm{kVAr}$ ) are provided to deliver margin for motor start requirements of experimental equipment proposed for the SBRC (but not included in demand calculations summarized in Table I). Fig. 2 illustrates the proposed PFC switching operations and reactive power demand for a nominal day using example building data. It is proposed that the PFC capacitor control remains unaltered for both gridconnected and islanded modes. However, during islanded mode it is necessary to provide additional reactive power demand from energy storage and/or localized generation. This requirement is included in sizing of energy storage.

\section{3) Sizing energy storage (Li-Ion battery bank)}

Several strategies can be considered when sizing energy storage; peak demand reduction, energy harvesting to reduce export, mitigating intermittent grid outages, and standalone operation. Each strategy has differing demand on energy storage sizing and economic constraints. For the SBRC microgrid standalone operation is desired for demonstration and research purposes (while still utilizing the grid for reliability). Sizing energy storage for prolonged intentional islanding is not required for the SBRC, and in order to minimize the energy storage requirement (due to financial constraints), intentional islanded operation is limited to single day demonstration. During the intentional islanded period it is expected to have load shedding procedures in place. Li-Ion batteries are the selected energy storage technology due to their high performance and material considerations associated with building certification [17].

The expected demand profile of the SBRC is plotted against the solar-PV localized generation (inverter output) to assist in establishing energy storage requirements, as shown in Fig. 3. The localized generation is based on solar-PV design and weather data from the previous 5-years, with minimum monthly average insolation data utilized to provide margin in energy storage requirements. The reactive power requirement is also allowed for in battery sizing. From Fig. 3 it is estimated that the energy requirement from the batteries will vary from $60 \mathrm{kWh}$ to $300 \mathrm{kWh}$ depending on available generation. It is anticipated that appropriate capacity will lie somewhere between these figures.

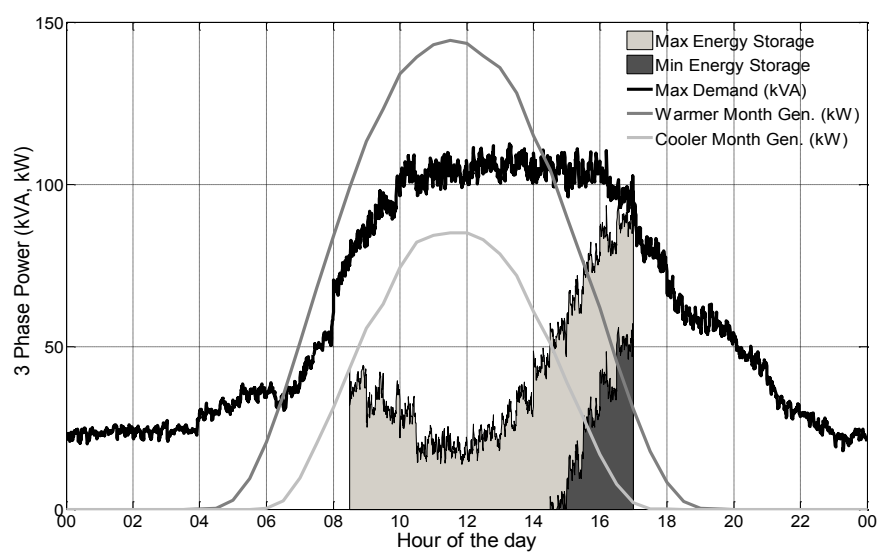

Fig. 3: Commercial building demand profile and estimated localized generation based on minimum monthly average insolation.

For preliminary design $100 \mathrm{kWh}$ is selected as the capacity, with intentional transition to islanded mode dependent on state of charge (SOC), available generation (weather forecast) and load shedding. Extending islanded mode operation may in the future may be made possible by increasing energy storage or localized generation. 


\section{A. SBRC Microgrid Layout}

A schematic of the SBRC microgrid model is shown in Fig. 4. Within the SBRC building measuring instruments have been placed at each source and office circuits in order to obtain real time measurements on generation and load.

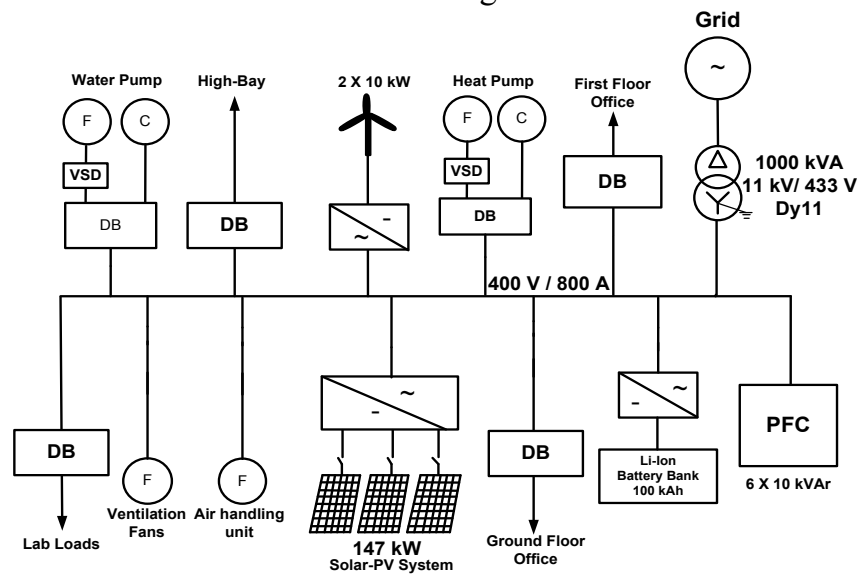

Fig. 4: Schematic of the SBRC microgrid.

Generating sources in the SBRC microgrid are comprised of $147 \mathrm{~kW}$ of rooftop solar-PV system and two wind generators $(2 \times 10 \mathrm{~kW})$. A $100 \mathrm{kAh}$ lithium-ion battery bank is employed as the main energy storage system for the microgrid. The generation capacity of the SBRC microgrid is summarized in Table II

Table II: Generation and storage capability of the SBRC microgrid

\begin{tabular}{c|c}
\hline \hline Generation & Load \\
\hline Solar-PV System & $147 \mathrm{~kW}$ \\
\hline Wind Generator (PMSG) & $2 \times 10 \mathrm{~kW}$ \\
\hline Battery storage (Li-ion) & $100 \mathrm{kAh}$ \\
\hline \hline
\end{tabular}

\section{SBRC DYNAMIC SIMULATION MODEL}

A dynamic simulation model was developed in DIgSILENT Power Factory considering the dynamics associated with the various generators and loads connected to the SBRC microgrid. A $60 \mathrm{kVAr}$ switched capacitor bank provides steady-state reactive power requirement for the microgrid which is comprised of six-steps and switched based on microgrid common busbar voltage with a $500 \mathrm{~ms}$ delay. The dynamic models of various generators and loads are described in subsequent sections.

\section{A. Modelling of Generation Sources}

\section{1) Solar-PV System}

The SBRC solar-PV system is physically comprised of three separate three-phase inverter systems. All three inverter systems are connected in parallel. However, this was modeled as a single $147 \mathrm{~kW}$ solar-PV inverter system in the simulation model. The current source model of the generic static generator model in the DIgSILENT Power Factory [19] has been adopted to develop the solar-PV model. The solar-PV model is comprised of the PV-array with embedded maximum power-point tracking (MPPT), DC-link and power controller. The controller is capable of controlling the voltage and frequency of the microgrid based on the reference values provided by the mode transition control system.
2) Wind Generation System

A permanent magnet synchronous generator (PMSG) based wind generator was modeled with a fully-rated converter. As the PMSG is comprised of a fully rated inverter, the mechanical-side dynamics are decoupled from electrical dynamics; therefore the wind turbine mechanical system was ignored in the dynamic simulation model.

\section{3) Battery Storage System}

A Li-Ion battery bank was modeled with a battery model and a converter model rated at $100 \mathrm{~kW}$. The charging characteristics are incorporated to the battery model while the active and the reactive power control capabilities are incorporated to the converter model. It must be noted that battery storage system is capable of controlling the microgrid voltage and frequency based on the references provided by the mode transition control system (see Fig. 7).

\section{B. Modelling of Loads}

\section{1) VSD Motor Loads}

There are number of VSD driven motor loads are connected to the SBRC microgrid. The main VSD motor loads include condenser fans at the heat pump unit $(2 \times 4 \mathrm{~kW})$, water pumps $(1.5 \mathrm{~kW})$ and air handling unit plenum fans $(2 \times 4 \mathrm{~kW})$. The VSD was modeled with a front-end controlled rectifier and an inverter system, while their load dynamics were represented by respective load characteristics (i.e. fan and pump models see Fig. 5).

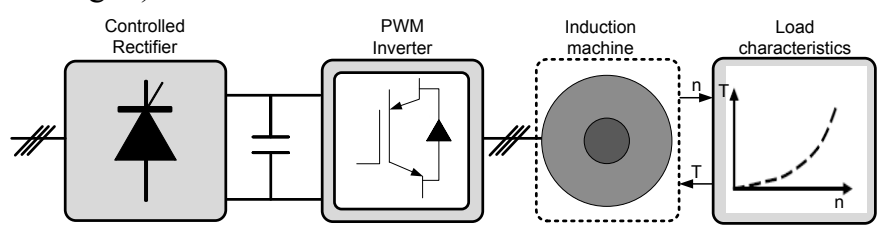

Fig.5: The VSD motor load model developed in DIgSILENT power factory.

\section{2) DOL Motor Loads}

The direct-on-line (DOL) induction motor load is the most dominant load component in the microgrid, as the heat pump unit is comprised of two scroll compressors each rated at $43 \mathrm{~kW}$. These motor loads were modeled with an induction motor model and incorporated the respective load characteristics (i.e. fan and pump models) in order to replicate the actual load behavior. In addition, soft-starter has also modeled at the front end of the induction motor.

\section{3) Computer, Lighting and Lab loads}

The complex load model given in DIgSILENT power factory [19] has been employed to represent the other loads in the SBRC microgrid. The load parameters shown in Table III have been adopted in order to represent the loads located at the ground floor office, first floor office, high-bay area and lab loads, where a, b and c represent the proportion of the lighting load, computer load and lab load respectively. Parameters (i.e. voltage dependencies) for each load type have been derived from [20].

Table III: Exponential load model

\begin{tabular}{l|c|c|c}
\hline \hline & $\mathrm{a}$ & $\mathrm{b}$ & $\mathrm{c}$ \\
\hline Ground floor office & 0.29 & 0.71 & 0 \\
\hline First floor office & 0.29 & 0.71 & 0 \\
\hline Ground floor labs & 0.02 & 0.1 & 0.98 \\
\hline High-bay area & 0.41 & 0 & 0.59 \\
\hline \hline
\end{tabular}




\section{CONCEPTUAl Framework For Mode Transition STRATEGY}

Microgrid mode transition can be categorized into two types; grid connected to islanded mode and islanded to grid connected mode. In each type, the transition strategy must be designed to ensure smooth transition without leading to any abnormal operating conditions in the microgrid. However, the scope of this study is limited to the mode transfer from gridconnected to islanded mode as it has been identified as the most challenging control issue for the microgrid, since the microgrid is suddenly subjected to large voltage magnitude and angle variations soon after disconnection from the grid $[16,18]$ and creates undesirable operating conditions for the connected loads. The grid connected to islanded mode can be classified into two types: (i) planned islanding; and (ii) unplanned islanding. Though the transition is a single process it is essential to design separate transition strategies due to unique characteristics associated with each outage type.

\section{A. Planned islanding (Planned Outages)}

The planned outages are determined based on the grid-side ancillary service requirements and planned network outage conditions, such as service outages for distribution feeders. Therefore, the mode transition strategy must be prudently planned based on the forecasted generation surplus/deficit in the microgrid system. The controller must consider available generation capacity, energy storage system state-of-charge (SOC) and forecasted load demand of the microgrid system prior carrying out the mode transition. Therefore, based on the available information, the controller will carry out a sequence of decisions to match the generation with the load demand prior executing the transition from the grid connected to islanded mode. Fig. 6 illustrates the flowchart of the mode transition strategy developed for planned outages.

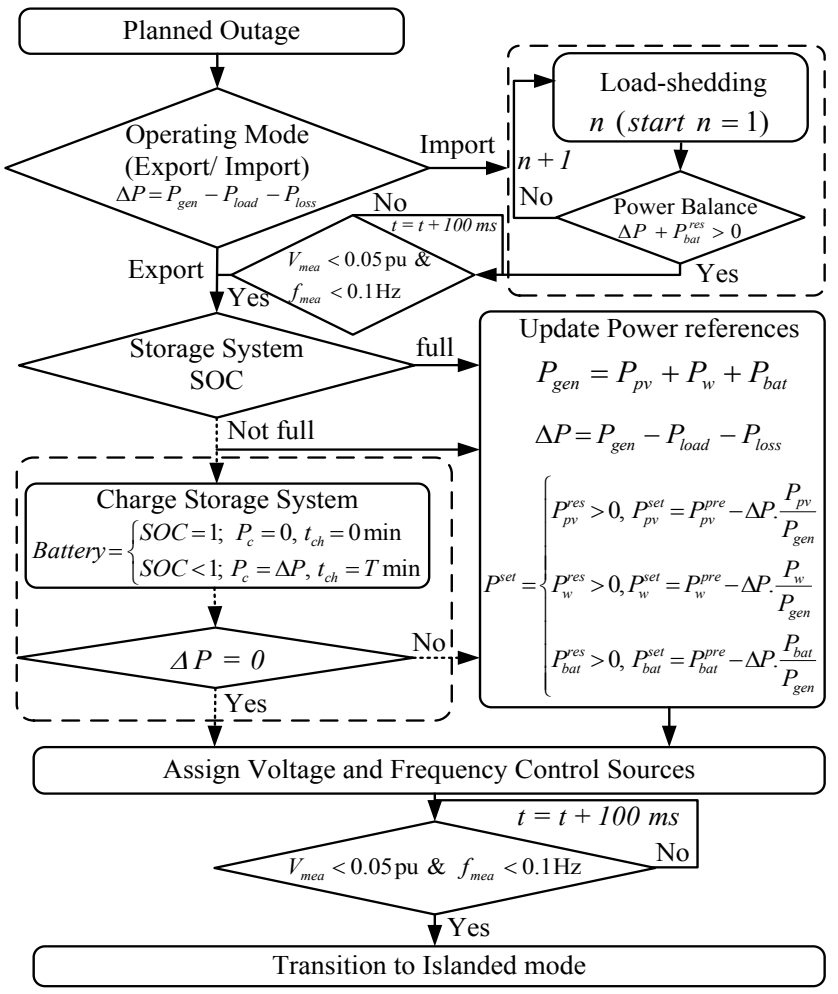

Fig 6: Flow diagram of the mode transition strategy. where $P_{\text {gen }}, P_{\text {load }}, P_{\text {loss }}, P_{p v}, P_{w}, P_{\text {bat }}, \Delta P, P_{c}, V_{\text {mea }}, f_{\text {mea }}, t_{c h}, n$ denote total power generation, total load demand, total losses, solar-PV generation, wind power generation, power output of the battery storage unit, generation demand imbalance, battery storage system charging power, voltage measured at the microgrid common busbar, frequency measurement at the microgrid common busbar, charging time and load shedding sequence respectively. Superscripts res, set, pre denote reserve, new reference, and reference prior to mode transition, respectively. Prior to mode transition, the microgrid decision management system (DMS) determines the operating mode (i.e. whether import or export). When the microgrid is operating at power import mode it is not able to meet the energy demand in the network, hence in order to match the generation with the load demand, a load shedding scheme must be implemented (refer to Table IV). The load shedding scheme is implemented in a sequential manner after detecting a power deficit, until energy surplus is achieved.

Table IV: Load-shedding sequence

\begin{tabular}{c|c|c}
\hline \hline Sequence (n) & Load type & $\begin{array}{c}\text { Maximum power } \\
\text { rating }\end{array}$ \\
\hline 1 & Heat-pumps (DOL) & $86 \mathrm{~kW}$ \\
\hline 2 & VSD pumps & $21.4 \mathrm{~kW}$ \\
\hline 3 & Non-essential lab equipment & $15 \mathrm{~kW}$ \\
\hline 4 & Lighting loads & $25 \mathrm{~kW}$ \\
\hline \hline
\end{tabular}

It should be noted that the computer loads and essential lab equipments are not considered in the load shedding scheme as they are required to be online under all circumstances. In addition, for each load shedding sequence there is a sub sequence which is capable to isolate the individual loads categorized under same type. For an example, there are two heat pumps operating at the SBRC microgrid, therefore the DMS will decide one or both should be made offline prior to mode transition. Following each load shedding step the microgrid power balance is evaluated, and once the voltage and frequency of the microgrid are stabilized below the specified value (i.e. $V_{\text {mea }}<0.05 \mathrm{pu}$ and $f_{\text {mea }}<0.1 \mathrm{~Hz}$ ), storage system SOC is evaluated.

Furthermore, as the microgrid is designed to achieve net zero energy target, the majority of the storage system capacity is also utilized for delivering power to local loads during power import mode in order to minimize power import. As illustrated in Fig. 6 if the storage system $S O C<1$, then battery can be charged till time of disconnection and subsequently excess generation $(\Delta P)$ can be curtailed based on the existing dispatch level from each generating source. The charging time $T$ must be decided based on the available time period till the time of planned outage. However, it must be noted that battery charging is an optional decision for the microgrid system. It should also be noted that as the SBRC microgrid is operating at net zero energy target, available local storage capacity in the microgrid system is kept at a minimum value during power import mode, hence the microgrid is designed to maintain a minimum of $10 \mathrm{kAh}$ reserve at the battery storage unit.

Then new power references are assigned to the generation sources (i.e. $P_{\text {ref } p v}, P_{\text {ref bat }}, P_{\text {ref } \_} w$ ) in order to match the generation with the load demand of the microgrid system. Once the power balance is established after assigning the new power references, voltage and frequency control schemes are established in order to control the voltage and frequency of the 
microgrid for seamless mode transition and islanded operation. The voltage and frequency control responsibilities are assigned to the generation sources based on the available active and reactive power reserves of the generation sources (see Fig. 6). After stabilizing the microgrid voltage and frequency below a predefined value (i.e. $V_{\text {mea }}<0.05 \mathrm{pu}$ and $f_{\text {mea }}<0.1 \mathrm{~Hz}$ ) mode transition is executed.

\section{B. Forced/Unplanned Islanding}

Unplanned islanding conditions mainly occur due to undesirable network conditions (i.e. during large voltage or frequency variations), hence microgrid must be designed to continuously monitor these variations and subsequently switch to the islanded mode to maintain uninterruptible supply to the microgrid loads. During such undesirable network conditions, voltage and frequency variations create adverse operating conditions for loads operating in the microgrid system. For a successful mode transition, the microgrid generation must be matched with the load demand in order to alleviate transients in the microgrid. The transition strategy outlined in Fig. 6 is adapted for the unplanned islanding with several control modifications. The voltage and frequency stabilizing loops in Fig. 5 are disregarded during unplanned islanding conditions.

\section{Control Scheme to Facilitate Mode Transition}

A multi-droop based control scheme was designed in order to assign and control the frequency of the microgrid during mode transition and islanded operation (see Fig. 7).

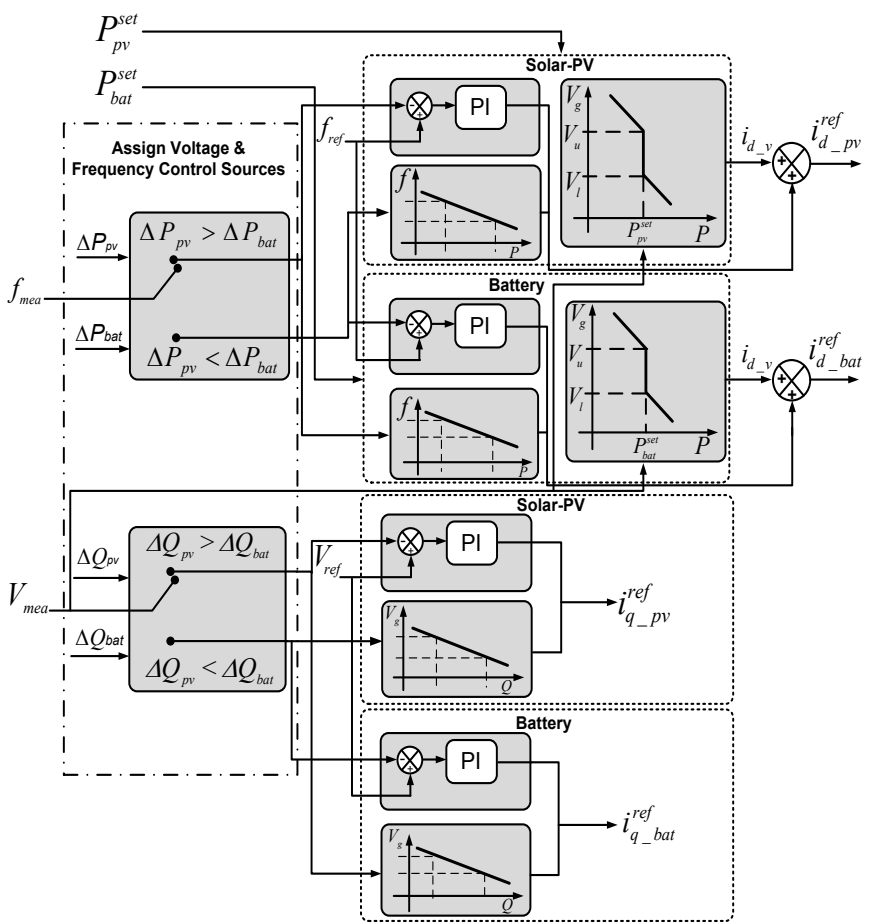

Fig. 7: Control strategy for mode transition.

The droop control is adopted as the main control mechanism to generate active and reactive power references to control frequency and voltage of the microgrid. As outlined in Fig. 6 once new power references are assigned to the generating sources voltage and frequency control responsibilities are assigned to the generation sources based on the highest available active $(\mathrm{kW})$ and reactive $(\mathrm{kVAr})$ power reserve (e.g. if $\Delta P_{p v}>\Delta P_{b a t}$ then the solar-PV units control the frequency based on PI controller while the battery storage generate the reference using a frequency droop controller) in the solar-PV and battery storage unit. However, it must be noted that size of the wind generator units is relatively small compared to the solar-PV unit and battery energy storage system; hence it has not been considered in the mode transition control scheme. However, it will control terminal voltage locally based on local reference and available reactive power reserve in the PMSG.

Furthermore, as the $X / R$ ratio of the cables in the microgrid is low (mostly resistive), it is not viable to control the microgrid voltage using reactive power control, hence dual droop control has been adopted for the active power control. Therefore, when voltage at the microgrid point of common coupling (PCC) deviates from the voltage dead-band (i.e. $0.98 \mathrm{pu}<V_{g}<1.02 \mathrm{pu}$ ), active power is also controlled to maintain the voltage due to low $\mathrm{X} / \mathrm{R}$ ratio. As the generating sources are controlled in the $d q$-reference frame, the $d$-axis current is controlled in order to control the active power; hence $d$-axis current reference for the solar-PV system is derived as follows:

$i_{d_{-} p v}^{r e f}= \begin{cases}\Delta P_{p v}>\Delta P_{b a t} ; & k\left(f_{e r r}\right)+\frac{1}{T_{n}} \int_{t}^{t+T_{n}} f_{e r r} d t+i_{d_{-} v} \\ \Delta P_{p v}<\Delta P_{b a t} ; & m\left(f_{\text {ref }}-f_{\text {mea }}\right)+P_{p v}^{s e t}+i_{d_{-} v}\end{cases}$

where $f_{\text {err }}, f_{\text {ref }}, f_{\text {mea }}, T_{n}, k$, and $m$ denote frequency error $\left(f_{\text {ref }}-f_{\text {mea }}\right)$, reference frequency, measured frequency at the SBRC, integration time constant, proportional gain, and frequency droop constant respectively. $i_{d v}$ denotes the output from the voltage-droop, which is defined as follows:

$$
i_{d_{-} v}=\left\{\begin{array}{l}
V_{u}>V_{\text {mea }}>V_{l} ; 0 \\
V_{u}<V_{\text {mea }} ; P_{p v}^{\text {set }}-n\left(V_{\text {mea }}-V_{u}\right) \\
V_{l}>V_{\text {mea }} ; P_{p v}^{\text {set }}+n\left(V_{l}-V_{\text {mea }}\right)
\end{array}\right.
$$

where $V_{u}, V_{l}, V_{\text {mea }}$ and $n$ denote upper voltage limit, lower voltage limit, voltage measurement and voltage droop respectively.

In order to control reactive power q-axis current reference is controlled which is determined for the solar PV system as follows:

$$
i_{q_{-} p v}^{r e f}= \begin{cases}\Delta Q_{p v}>\Delta Q_{b a t} ; & k\left(V_{e r r}\right)+\frac{1}{T_{m}} \int_{t}^{t+T_{m}} V_{e r r} d t \\ \Delta Q_{p v}<\Delta Q_{b a t} ; & s\left(V_{r e f}-V_{\text {mea }}\right)+Q_{p v}^{s e t}\end{cases}
$$

where $V_{e r r}, V_{r e f}, T_{m}$, and $s$ denote voltage error $\left(V_{\text {ref }}-V_{\text {mea }}\right)$, reference voltage, integration time constant and voltage droop respectively. Similar functions can be derived for the battery energy storage system.

\section{Controller Performance}

In order to evaluate the controller performance a planned outage was simulated for the SBRC microgrid model with $70 \%$ load (all VSD and DOL motor loads are online). Prior to the planned outage it is assumed that microgrid is operating at its full generation capacity $(267 \mathrm{~kW})$ and transition process was initiated at $t=2 \mathrm{~s}$. Fig. 8 illustrates the control decision calculation process of the mode transition strategy. 

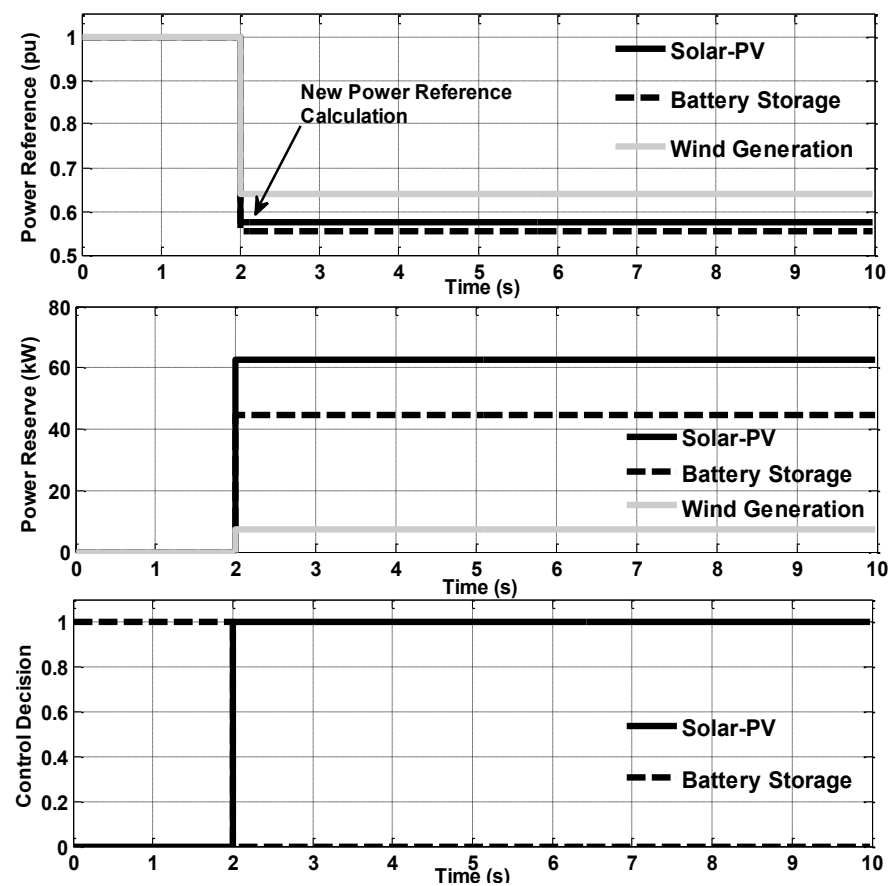

Fig. 8: Control decision formulation of the mode transition strategy.

Once the planned outage is initiated new power references are calculated and assigned for the generation sources directly without making any charging decision, since battery energy storage SOC is at 1 . Subsequently, available active power reserve at each generation source is calculated to determine the frequency control strategy for the microgrid system. In Fig. 8 control decision 1 denotes $\Delta P_{p v}>\Delta P_{b a t}$ while $\Delta P_{p v}<$ $\Delta P_{\text {bat }}$ is denoted by 0 . Therefore, as illustrated in Fig. 8 solar PV system has taken the primary responsibility to control network frequency while the battery energy storage system will contribute in droop mode. Fig. 9 illustrates the control signals generated at solar-PV and battery energy storage system.
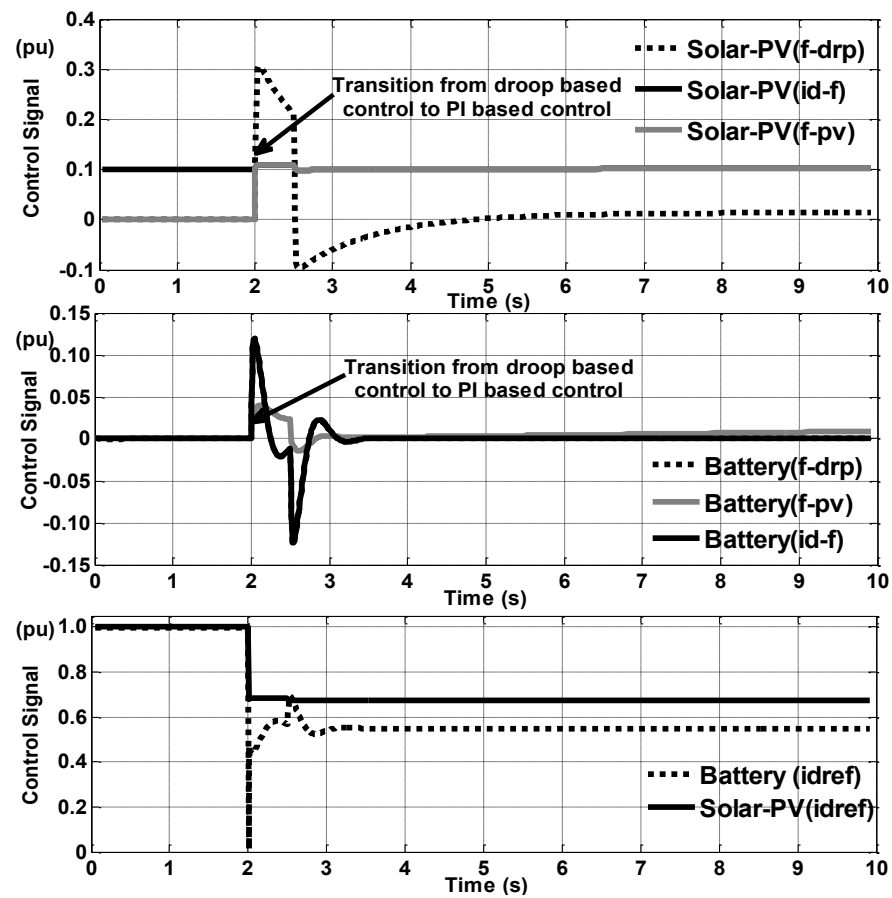

Fig. 9: Active power control signals of the generation sources.
According to Fig. 9 when transition process is initiated solar-PV system started to control the microgrid frequency based on PI controller output while switching from the droop control scheme as the inverter associated with the solar-PV system has much larger reserve. Contrary, based on the control decision of the transition strategy, battery storage system has switched to the droop control mode.

\section{Dynamic Performance Evaluation}

The dynamic performance of the mode transition strategy was evaluated under planned and forced outage conditions. The simulations have been performed assuming the worst possible scenarios for the SBRC microgrid; hence a load demand scenarios greater than the expected peak demand for the SBRC microgrid was investigated in the simulations.

\section{A. Planned Outages}

The planned outages follow the transition strategy outlined in Fig. 6. Furthermore, power export was maintained at approximately $50 \mathrm{~kW}$ for each load scenario. For power export mode several load scenarios were considered (i.e. load proportions of $0.5,0.7$ and 1 as a ratio of total installed load in the microgrid). As outlined in Section III, charging the battery storage unit is an optional requirement, hence that was not considered here. Mode transition was initiated at $\mathrm{t}=1 \mathrm{~s}$ and soon after initiation new power references are assigned to the generation sources in order to achieve power balance in the microgrid (see Fig. 10).

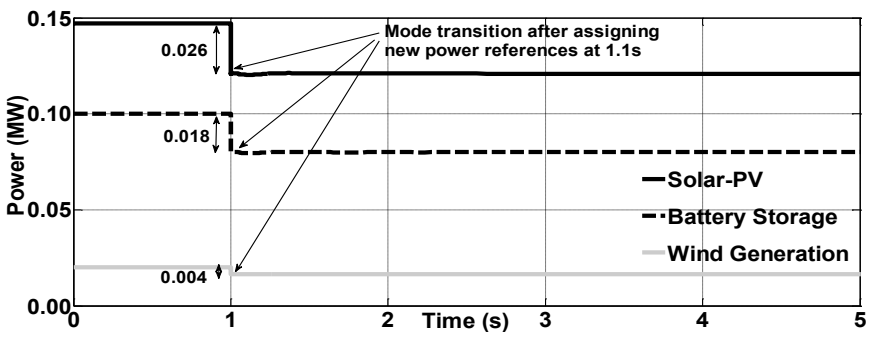

Fig. 10: Active power response of generator units during mode transition for maximum load $(214 \mathrm{~kW})$.

As illustrated in Fig. 10 once the transition strategy is implemented the generating sources are assigned with new power references based on their exiting generation and ultimately power generation is curtailed to match with the load demand of the microgrid system.
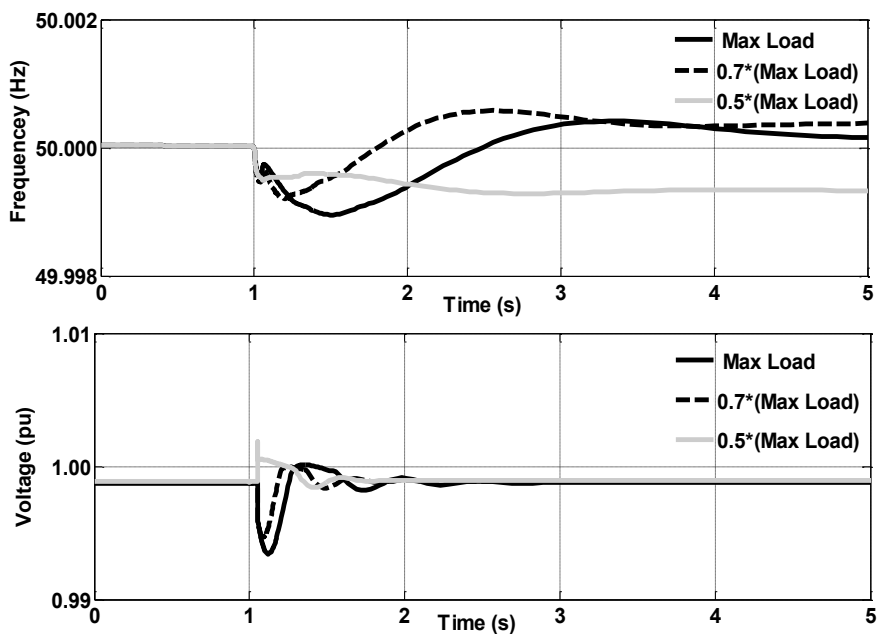

Fig. 11: Microgrid Frequency and voltage response following a planned outage during the power export mode. 
After curtailing the power generation system parameters are verified against the stipulated limits (i.e. $V_{\text {mea }}<0.05 \mathrm{pu}$ and $f_{\text {mea }}<0.1 \mathrm{~Hz}$ ) to ensure voltage and frequency stability of the microgrid, and subsequently the transition process is executed. The voltage and frequency variations for various power export scenarios are illustrated in Fig. 11. According to Fig. 11 the planned outage has indicated minimal an impact on SBRC voltage and frequency. For an example, it has indicated only a $0.005 \mathrm{pu}$ voltage drop and $0.001 \mathrm{~Hz}$ frequency variation following the mode transition even under worst possible operating conditions (i.e. maximum installed load).

Furthermore, simulations have been carried out considering maximum load scenario and assuming a power import of $50 \mathrm{~kW}$ to verify the mode transition strategy for power import scenario. The voltage and frequency variations for power import scenario are illustrated in Fig. 12.
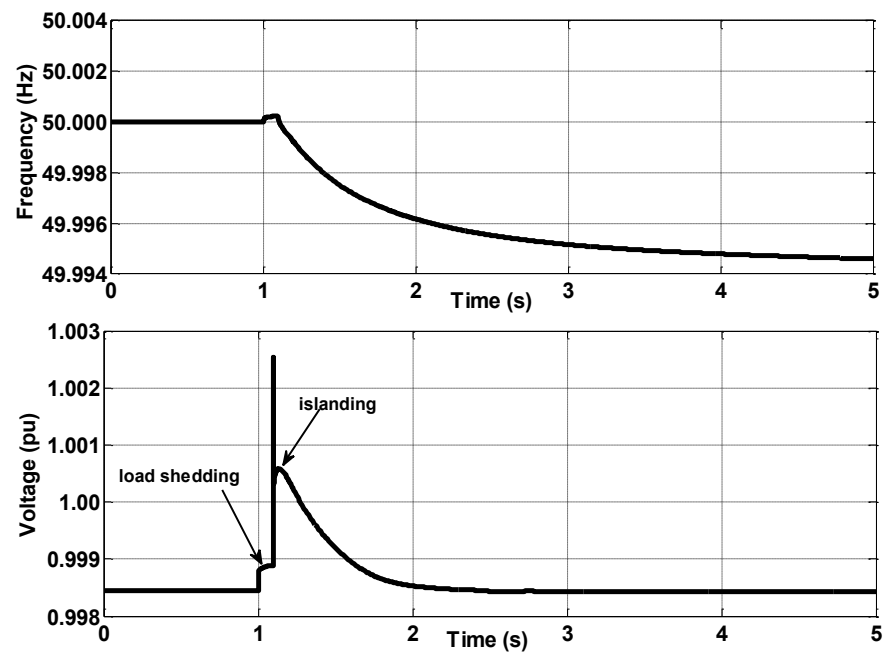

Fig. 12: Microgrid Frequency and voltage response following a planned outage during the power import mode.

Once the planned outage is initiated at $t=1 \mathrm{~s}$, the load shedding scheme is implemented as the microgrid generation is not sufficient to meet the load demand. Therefore, one of the $43 \mathrm{~kW}$ heat pump units was taken offline, and subsequently with the aid of additional battery storage capacity, the microgrid generation is matched with the load. Then after $100 \mathrm{~ms}$ the microgrid voltage and frequencies were stabilized below the stipulated limits, and subsequently the microgrid islanded from main grid.

\section{B. Forced Outages}

Performance of the mode transition strategy during forced outages was investigated considering the power export and import scenarios for the microgrid system. It should be noted that during power export mode the office, lab and high-bay area loads are assumed to be operating at $0.8 \mathrm{pu}$ while all the motor loads are assumed to be online. Both wind and solar-PV generation is at their maximum capacity and the battery storage system also provides 0.9 pu active power output to the grid. Therefore, microgrid exports $20 \mathrm{~kW}$ active power to the main grid. During power import mode it is assumed that the microgrid is operating at its peak load while the total generation is $181 \mathrm{~kW}$. Therefore, the microgrid imports $33.4 \mathrm{~kW}$ from the main grid prior to the forced outage. In both scenarios outage was initiated at $t=1 \mathrm{~s}$ and voltage and frequency variations are shown in Fig. 13.
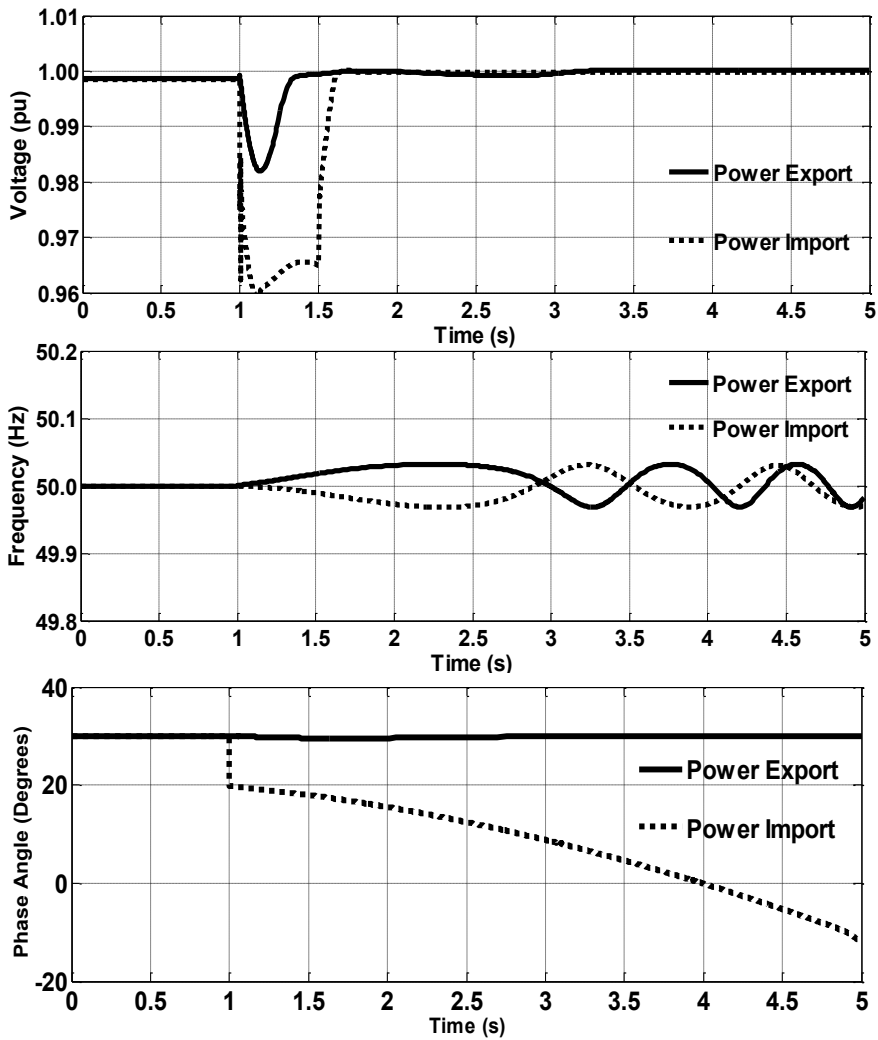

Fig. 13: Microgrid response during forced outages.

When forced outage occurs during power import mode, a $43 \mathrm{~kW}$ DOL heat pump was taken offline as the total power generation at the SBRC exceeds the local power demand. As shown in Fig. 13, $\pm 0.05 \mathrm{~Hz}$ frequency oscillations can be observed in the microgrid system. In addition, when the forced outage occurs during power import mode the VSD motor loads in the microgrid are subjected to commutation failure due to the large voltage drop and phase angle variations at their terminals. For example, when the forced outage occurs during power import mode it has indicated an instantaneous phase angle shift of $10^{\circ}$, which has significantly contributed towards the commutation failure at the VSD motor loads. Therefore, the VSD motor loads are disconnected from the microgrid during power import conditions (see Fig. 14).

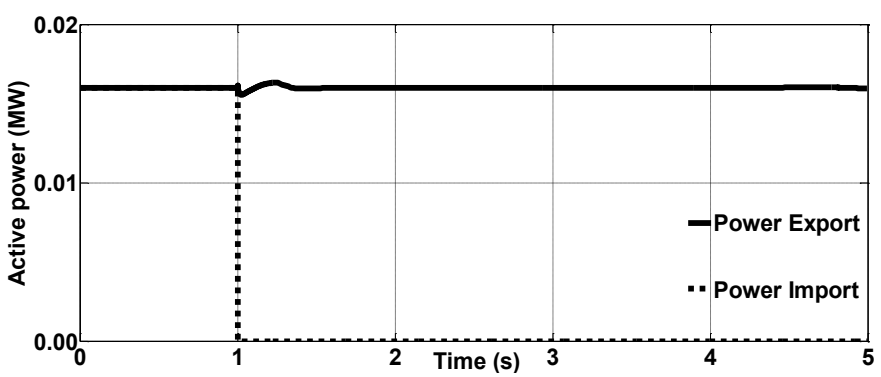

Fig 14: Response of the VSD motor loads during forced outages.

The DOL motor loads are operating during mode-transition absorbing reactive power from grid which has resulted in substantial voltage dip (e.g. 0.04 pu during power import). However, the microgrid voltage recovers with the reactive power support provided by the battery storage inverter unit. As shown in Fig. 15, the solar-PV unit curtails generation during power import mode in order match the generation with the load demand. However, in terms of the battery storage 
system, it supports microgrid voltage by injecting reactive power.
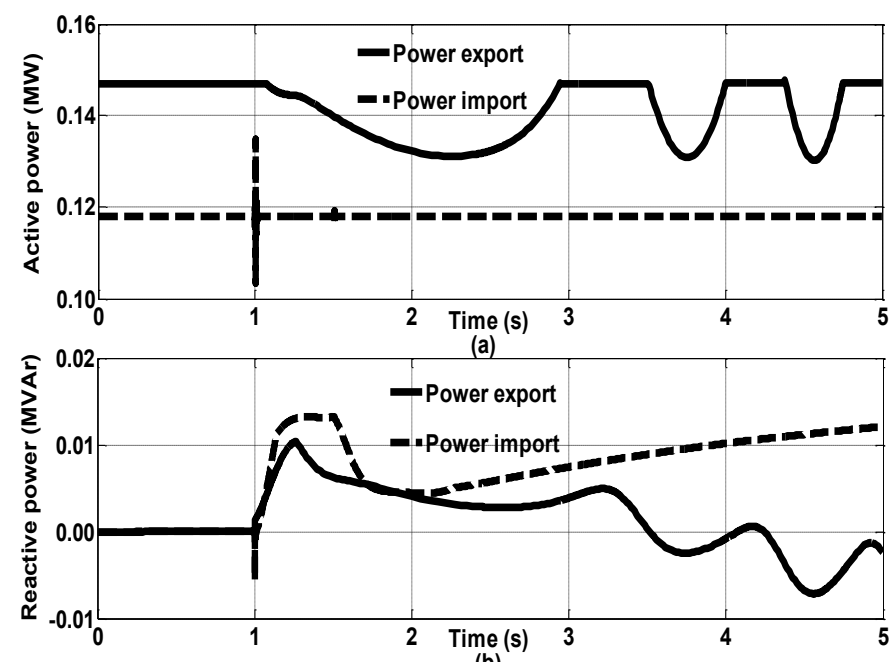

(b)

Fig. 15: Response during forced outages; (a) solar-PV, (b) battery storage.

\section{OTHER PRACTICAL ASPECTS For SBRC MicRogRID}

\section{A. Connection Agreements}

Connection agreements from Australian utilities generally apply several requirements for connection of microgrids: general protection; voltage rise; anti-islanding protection (where applicable); and general safety (labeling, etc.). The main constraint for connection to downstream parts network is voltage rise requirements. Constraints on voltage rise are also written into the electricity wiring rules. Since most of the commercial building microgrids are of small scale, more onerous generator and energy market participation requirements are omitted from the connection agreements with the utility.

\section{B. Financial Constraints}

Generally, commercial building microgrids will not be large enough to participate in the electricity market, and energy prices for exporting power to the grid are negotiated directly with the retailers. In Australia, energy export prices are generally a fraction of energy import prices and net-metering pricing schemes are used. Microgrids which delay or negate network upgrades and enhance network support may be eligible for compensation from utilities under the connection agreement. Due to the low energy export prices, utilizing excess energy production from the SBRC facility within the University precinct is a priority. Accordingly, the connection of the SBRC microgrid at the LV level with several adjacent building loads may be able to absorb the local generation. In this manner, the financial benefits improve the returns based on energy import prices as opposed to energy export.

\section{Protection Adequacy}

Although not addressed in this work, protection adequacy needs to be considered for both the utility and within the commercial building or precinct network, with the latter being imperative if islanded mode is to be implemented. Nonstandard LV network protection grading may be required for reverse power-flow scenarios (i.e. energy export). Protection adequacy may include an additional requirement to facilitate intentional transition to islanded mode.

\section{CONCLUSIONS}

This paper has investigated the design, operational and control requirements and strategies required for a commercial building microgrid installation for a seamless mode transition. The design philosophy is based around net zero energy target for the microgrid. The frequency and voltage control strategies have been proposed to ensure an islanded operation of the microgrid and multi-droop control mechanism has been developed for seamless mode transition. However, such capabilities may not be required during the grid connected operation, wherein relatively robust network conditions are expected. The outcomes of the study presented in this paper highlight the necessity of different operational settings for both islanded and grid connected operation of the commercial scale SBRC microgrid under different system conditions.

\section{REFERENCES}

[1] B. Kroposki, R. Lasseter, T. Ise, S. Morozumi, S. Papatlianassiou, N. Hatziargyriou, "Making Microgrids Work" IEEE Power Energy Magazine, pp. 40-53, May/June 2008.

[2] N.W.A. Lidula, A.D. Rajapakse, "Microgrids research: A review of experimental microgrids and test systems" Renewable and Sustainable Energy Reviews, vol. 15, pp. 186-202, 2011.

[3] E. Joseph, R. Lasseter, B. Schenkman, J. Stevens, H. Volkommer, D. Klapp, et al. "CERTS microgrid laboratory testbed," Consortium for Electric Reliability Technology Solutions (CERTS), CEC-500, 2008.

[4] M. Barnes, A. Dimeas, A. Engler, C. Fitzer, N. Hatziargyriou, C. Jones, et al. "Microgrid laboratory facilities," IEEE Int. conf. future power syst., Amsterdam, Netherlands, Nov. 2005.

[5] T. Erge, R. Becker, A. Kro"ger-Vodde, H. Laukamp, M. Thoma, R. Werner, et al. "Report on improved power management in low voltage grids by the application of the PoMS system," Dispower, 2006.

[6] T. Loix, K.U. Leuven, "The first micro grid in the Netherlands: Bronsbergen," Feb. 2009, [online] Available: http://www.leonardo energy.org/webfm_send/493.

[7] I. Mitra, T. Degner, M. Braun, "Distributed generation and microgrids for small island electrification in developing countries: a review," SESI Journal. vol. 18, no. 1, pp. 6-20, 2008.

[8] S. Morozumi, H. Nakama, N. Inoue, "Demonstration projects for gridconnection issues in Japan," Elektrotechnik \& Informationstechnik, vol. 125, no. 12, pp. 426-31, 2008.

[9] X. Guan, Z. Xu, Q.S. Jia, "Energy-Efficient Buildings Facilitated by Microgrid," IEEE Trans. Smart Grid, vol. 1, no. 3, pp. 243-252, Dec. 2010.

[10]C.A. Hernandez-Aramburo, T.C. Green, N. Mugniot, "Fuel Consumption Minimization of a Microgrid," IEEE Trans. Industry Applications, vol. 41, no. 3, pp. 673-681, May/June 2005.

[11]I. Bae, J. Kim "Reliability Evaluation of Customers in a Microgrid," IEEE Trans. Power Syst., vol. 23, no. 3, pp. 1416-1422, Aug. 2008.

[12]G. Celli, F. Pilo, G. Pisano, G.G. Soma, "Optimal Participation of a Microgrid to the Energy Market with an Intelligent EMS," IEEE. In: $7^{\text {th }}$ International Power Engineering Conference (IPEC), 2005.

[13]G. Díaz, C. González-Morán, J. Gómez-Aleixandre, A. Diez, "Scheduling of Droop Coefficients for Frequency and Voltage Regulation in Isolated Microgrids," IEEE Trans, Power Syst., vol. 25, no. 1, pp. 489-496, Feb. 2010.

[14]R.H. Lasseter, J.H. Eto, B. Schenkman, J. Stevens, H. Vollkommer, D. Klapp, E. Linton, H. Hurtado, J. Roy, "CERTS Microgrid Laboratory Test Bed," IEEE Trans. Power Deli., vol. 26, no. 1, pp. 325-332, Jan. 2011.

[15]Y.A.R.I. Mohamed, A.A., Radwan, "Hierarchical Control System for Robust Microgrid Operation and Seamless Mode Transfer in Active Distribution Systems," IEEE Trans. Smart Grid, vol. 2, no. 2, pp. 352362, Jun. 2011.

[16]T.L. Vandoorn, B. Meersman, J.D.M. De Kooning, L. Vandevelde, "Transition from islanded to grid-connected mode of microgrids with voltage-based droop control," IEEE Trans. Power Syst. (in press)

[17]J.F. McLennan, "Living Building Challenge Standard 2.1," International Living Future Institute, Seattle, May 2012. 
[18]V. Jayawardana, L. Meegahapola, S. Perera, D. Robinson, "Dynamic Characteristics of a Hybrid Microgrid with Inverter and Non- Inverter Interfaced Renewable Energy Sources: A Case Study," IEEE POWERCON 2012, Auckland, New Zealand. Nov. 2012.

[19] Power Factory Manual, DIgSILENT Power Factory Version 14.1, GmbH, Germany, 2012.

[20]I. R. Navarro, "Dynamic Power System Load: Estimation of Parameters from Operational Data," PhD thesis, Lund university, 2005.

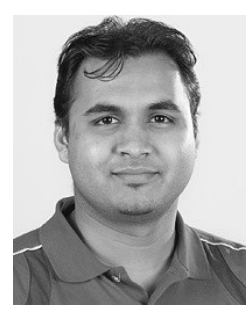

Lasantha Meegahapola (S'06, M'11) received his BSc.Eng.(Hons.) degree in Electrical Engineering (First Class) from the University of Moratuwa, Sri Lanka in 2006, and his $\mathrm{PhD}$ degree from Queen's University of Belfast, UK in 2010. His doctoral study was based on the investigation of power system stability issues with high wind penetration, and research was conducted in collaboration with EirGrid (Republic of Ireland-TSO). He was a visiting researcher in the Electricity Research Centre, University College Dublin, Ireland (2009/2010). Currently he is employed as a lecturer at the University of Wollongong. He is a member of IEEE and IEEE Power Engineering Society (PES).

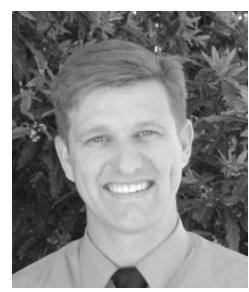

Duane Robinson graduated from the University of Wollongong with a B.E.(Hons.) in Electrical Engineering in 1998 after completing a seven year cadetship with the BHP Port Kembla Steelworks. In 2002 Duane took up a position as researcher with the Centre working on power quality related research projects for Integral Energy and other consulting activities, and later joined the University's academic staff as a Senior Lecturer. He temporarily departed the university to pursue more industrial experience, working for a multidisciplinary consulting firm primarily on LV and MV electrical distribution design, control, and protection projects for heavy industry clients. In 2011 he returned to the University to take up a new research interest in the area of energy efficiency and demand side integration with the Sustainable Buildings Research Centre, and to rejoin his colleagues at the Australian Power Quality and Reliability Centre.

A. P. Agalgaonkar (M'09-SM'13) received the B.E. (Electrical Engineering) and M.E. (Electrical Power System) degrees from Walchand College of

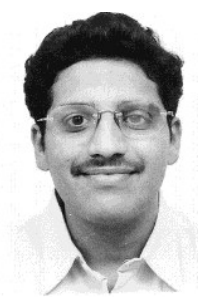
Engineering, Sangli, India, in 1997 and 2002, respectively, and the Ph.D. degree in Energy Systems Engineering from the Indian Institute of TechnologyBombay, Mumbai, India, in 2006. He was a Scientist at the Energy Technology Centre, NTPC Ltd., Greater Noida, India, from 2005 to 2007. In February 2008, he took up a position with the University of Wollongong, in Wollongong, Australia, as a Postdoctoral Research Fellow. Currently, he is a Lecturer at the University of Wollongong. His research interests include planning and operational aspects of renewable and distributed generation, microgrids, electricity markets and system stability

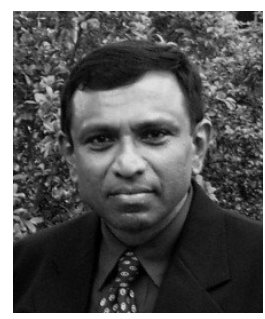

S. Perera (M'95, SM'13) received the B.Sc.(Eng.) degree in electrical power engineering from the University of Moratuwa, Sri Lanka, the M.Eng.Sc. degree in electrical engineering from the University of New South Wales, Australia, in 1978, and the $\mathrm{Ph} . \mathrm{D}$. degree in electrical engineering from the University of Wollongong, Wollongong, Australia, in 1988. He has been a Lecturer at the University of Moratuwa, Sri Lanka. Currently, he is a Professor at the School of Electrical, Computer and Telecommunications Engineering, University of Wollongong. He is the Technical Director of the Australian Power Quality and Reliability Centre, University of Wollongong.

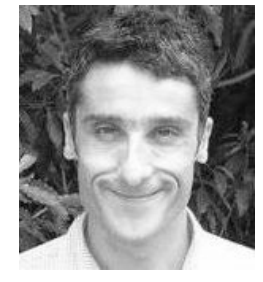

P. Ciufo (SM'07) received the B.E. (Hons.) and M.E. (Hons.) degrees in electrical engineering from the University of Wollongong, Wollongong, Australia, in 1990 and 1993, respectively, and the $\mathrm{Ph} . \mathrm{D}$. degree in electrical engineering in 2002. Dr . Ciufo has had various stints in industry as an Electrical Engineer and returned to academia in 2007. His research interests include modelling and analysis of power distribution systems, distribution automation, modelling and analysis of ac machines, power system harmonics, and power system reliability. 